\title{
Procedimentos estimativos do potencial de uso de chaminés solares para promover a ventilação natural em edificações de baixa altura
}

\author{
Procedures for estimating the potential use of solar \\ chimneys for natural ventilation enhancement in low-rise \\ buildings
}

\section{Leticia de Oliveira Neves Maurício Roriz}

\section{Resumo}

Leticia de Oliveira Neves Faculdade de Engenharia Civil, Arquitetura e Urbanismo. Universidade Estadual de Campinas Rua Des. Antão de Moraes, 1165 Campinas - SP - Brasi CEP 13083-310 Tel.: (11) 8516-9060 E-mail: leneves@gmail.com

Maurício Roriz Departamento de Engenharia Civil, Centro de Ciências Exatas e de Tecnologia Universidade Federal de São Carlos Via Washington Luís, Km 235 Caixa-Postal 67 São Carlos - SP - Brasil CEP 13565-905 Tel.: (16) 3351-8262 E-mail: m.roriz@terra.com.br

Recebido em 30/09/11

Aceito em 06/03/12

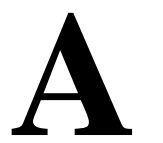

ventilação natural é uma das estratégias mais importantes para o condicionamento térmico passivo de ambientes internos de edificações, podendo ocorrer pela ação dos ventos, pelo efeito chaminé ou pela combinação de ambos. Em áreas urbanizadas, a velocidade do vento é sensivelmente reduzida pelos obstáculos locais, tornando o efeito chaminé uma alternativa de projeto mais viável, pois independe dos ventos. Este artigo tem por objetivo apresentar e discutir procedimentos estimativos do potencial de uso de chaminés solares para edificações de baixa altura, localizadas em regiões de baixa latitude. Desenvolveram-se previsões teóricas, através de um modelo matemático e de simulação computacional. Realizou-se um processo de calibração destes modelos, utilizando como referência os resultados do monitoramento experimental de uma célula de teste. $O$ processo baseou-se na análise comparativa de algumas variáveis selecionadas, considerando-se dados de temperatura superficial, temperatura do ar e vazão volumétrica no interior da chaminé. Os resultados indicaram que os modelos teóricos têm potencial de aplicação na avaliação do desempenho de chaminés solares, especialmente o modelo de simulação, em que foram observadas diferenças inferiores a $20 \%$ entre resultados medidos e calculados.

Palavras-chave: Chaminé solar. Ventilação natural. Efeito chaminé. Energia solar.

\section{Abstract}

Natural ventilation is one of the most important strategies for passive cooling of indoor environments. It can occur by wind forces, by stack effect or by a combination of both strategies. The second choice tends to be more effective in urban areas, where there are obstacles that block or significantly reduce wind speed. This paper analyses prediction procedures for the potential use of solar chimneys in low-rise buildings at low latitude locations. Theoretical predictions were developed using a mathematical model and computer simulation. A calibration procedure was used, based on results obtained through an experimental set up. The procedure consisted in a comparative analysis of chosen variables, considering data of surface temperature, air temperature and volumetric flow rate inside the chimney channel. The results confirmed the great potential of applicability of the theoretical models in the performance analysis of solar chimneys, especially the simulation model, which presented differences lower than $20 \%$ between measured and estimated results.

Keywords: Solar chimney. Natural ventilation. Stack effect. Solar energy. 


\section{Introdução}

A ventilação natural é uma estratégia importante para o resfriamento passivo de edificações. Em ambientes fechados, as temperaturas internas frequentemente ultrapassam as externas, em decorrência das fontes internas de calor e do aquecimento da envoltória por absorção da radiação solar. Nessas situações, a ventilação natural pode contribuir para o resfriamento do ambiente, substituindo o ar aquecido interno pelo ar mais fresco externo. $\mathrm{O}$ aumento da velocidade do ar na altura da zona ocupada pode também elevar as perdas de calor da pele, por convecção e por evaporação, provocando uma redução na sensação de calor. Desse modo, o vento pode reduzir o desconforto ocasionado por temperaturas e umidades mais elevadas (GIVONI, 1994).

A ventilação natural pode ocorrer através da ação direta dos ventos, do efeito chaminé ou da combinação de ambos. Em áreas urbanizadas, a velocidade do vento é sensivelmente reduzida pelos obstáculos locais, tornando o efeito chaminé uma alternativa de projeto mais viável, pois independe dos ventos. Mathur, Mathur e Anupma (2006) indicam a seguinte equação para a determinação da vazão de ar provocada pelo efeito chaminé:

$\mathrm{Q}=\mathrm{Cd} \cdot \mathrm{As} \sqrt{\frac{2 \cdot \mathrm{g} \cdot \mathrm{Ah}(\mathrm{Ti}-\mathrm{Te})}{\left(1+\mathrm{Ar}^{2}\right) \mathrm{Te}}}$

Eq. 1

Sendo:

$\mathrm{Q}=$ vazão volumétrica $\left(\mathrm{m}^{3} / \mathrm{s}\right)$;

$\mathrm{Cd}=$ coeficiente de descarga do conjunto de aberturas (adimensional);

As = área efetiva da abertura de saída do $\operatorname{ar}\left(\mathrm{m}^{2}\right)$;

$\mathrm{g}=$ aceleração da gravidade $\left(9,807 \mathrm{~m} / \mathrm{s}^{2}\right)$;

$\Delta \mathrm{h}=$ diferença de altura entre as aberturas de entrada e saída do ar (m)

$\mathrm{Ti}=$ temperatura do ar interno $(\mathrm{K})$;

$\mathrm{Te}=$ temperatura do ar externo $(\mathrm{K})$; e

$\mathrm{Ar}=$ razão entre as áreas de entrada e saída do ar (adimensional).

Pela equação, pode-se observar que a intensidade da ventilação obtida pelo efeito chaminé depende das relações entre diversos fatores, incluindo a diferença de temperatura entre os ambientes interno e externo, a diferença de altura entre as aberturas de entrada e saída do ar, e a área efetiva de abertura para ventilação.
O coeficiente de descarga representa as resistências por ação do atrito e da turbulência que ocorrem em um escoamento de fluido real, isto é, de viscosidade não nula. Essas resistências fazem com que parte da energia do escoamento seja convertida em calor, ocasionando uma redução na velocidade do fluido. Para o caso específico de edificações, Cóstola (2006) define-o como o parâmetro que permite descrever o comportamento da abertura e das obstruções junto dela, como os brises. Seu valor depende da geometria das aberturas e do canal de passagem do ar e do regime do escoamento, se laminar ou turbulento. Ainda há muita incerteza sobre os valores a serem atribuídos a essa variável.

Estudos demonstram que é de extrema relevância adotar um valor apropriado a cada situação, o que contraria a prática corrente de assumir um valor próximo de 0,6, independentemente do detalhamento das aberturas (MARQUES DA SILVA, 2003). Cóstola (2006) reafirma esse fato ao mencionar que a importância na correta definição de um valor para o coeficiente de descarga é a mesma que a da área de abertura, já que ele afeta linearmente a quantidade de energia disponível na abertura.

Uma forma de favorecer o movimento do ar por impulsão térmica dentro de edificações é através do uso da energia solar, para incrementar o diferencial de temperatura, visando intensificar o processo de exaustão do ar aquecido. Isso pode ser feito através de um tipo particular de chaminé, denominado chaminé solar. A estratégia torna-se especialmente vantajosa quando há pouca diferença de temperatura entre as aberturas de entrada e saída do ar, situação frequente em edificações de baixa altura.

A chaminé solar utiliza a energia proveniente da radiação solar para aquecer o ar e induzir o efeito chaminé, por meio do incremento das diferenças de pressão e temperatura entre a entrada e a saída do ar. Seu funcionamento envolve processos de transferência de calor por condução, convecção e radiação (Figura 1). O sistema é composto de um coletor solar com duas superfícies paralelas - uma cobertura de vidro na face superior e uma placa negra absorvedora na face inferior, com isolamento térmico na parte externa. Dessa forma, o aquecimento do ar no canal é incrementado pelo efeito estufa, induzindo o movimento ascendente do ar (ONG; CHOW, 2003). 


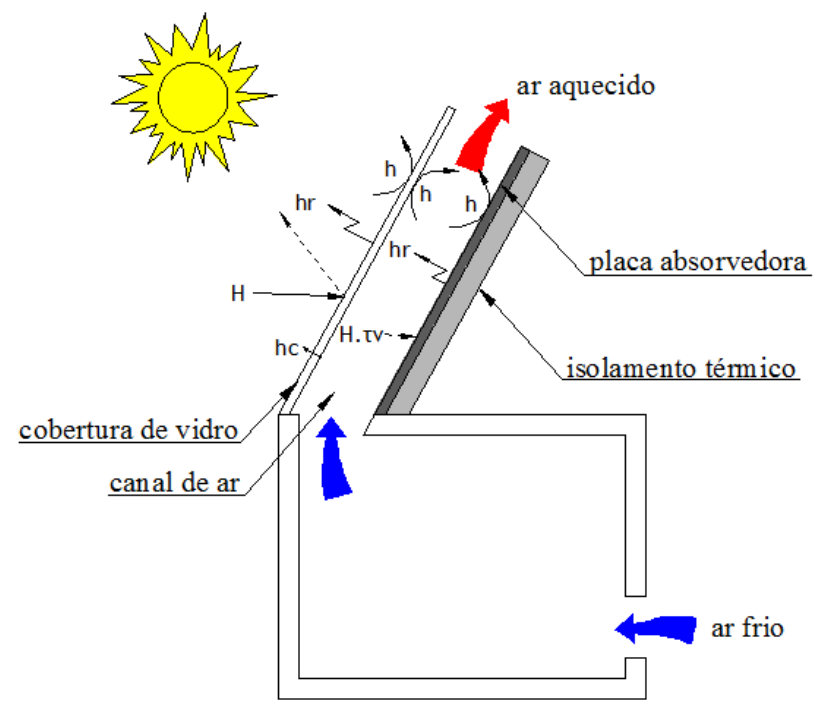

Figura 1 - Corte esquemático de uma chaminé solar inclinada

Sendo:

$\mathrm{H}=$ irradiância solar no vidro $(\mathrm{W} / \mathrm{m} 2)$;

$\tau \mathrm{V}=$ transmitância ótica do vidro (adimensional);

$\mathrm{h}=$ coeficiente de transferência de calor por convecção (W/m2.K);

hc $=$ coeficiente de transferência de calor por condução (W/m2.K); e

$\mathrm{hr}=$ coeficiente de transferência de calor por radiação $(\mathrm{W} / \mathrm{m} 2 . \mathrm{K})$.

O comportamento de uma chaminé solar está diretamente relacionado às taxas de ventilação e de transferência de calor que, por sua vez, dependem da configuração geométrica do sistema. Bassiouny e Korah (2008) evidenciam a importância das dimensões da chaminé - incluindo profundidade do canal de ar, diferença de altura entre aberturas de entrada e saída do ar e inclinação do coletor sobre os resultados de fluxo de ar e perfis de velocidade.

Para o cálculo do fluxo de ar por efeito chaminé, Andersen (1995) define um coeficiente de descarga específico para movimento de ar por impulsão térmica, amplamente utilizado nas pesquisas sobre chaminés solares, cujo valor é de 0,57. O cálculo baseia-se na multiplicação do coeficiente de velocidade, que leva em conta as perdas por fricção, pelo coeficiente de contração, que leva em conta a contração do fluxo de ar quando passa pela abertura.

Diversos autores comentam sobre a influência da relação entre a altura da chaminé e a espessura do canal de ar no incremento da vazão (CHEN et al., 2003; MATHUR et al., 2006, ONG; CHOW, 2003). Chen et al. (2003) concluíram que, se fossem ultrapassados certos limites, poderia ocorrer uma circulação inversa do ar, ou seja, um fluxo descendente pelo centro do duto. Os autores chegaram a uma profundidade crítica de $30 \mathrm{~cm}$. Adam (2003) afirma que esse limite depende do comprimento, da inclinação e da área de abertura da chaminé, bem como dos fluxos de calor.

A intensidade da radiação solar incidente na cobertura de vidro da chaminé também tem grande influência em seu desempenho. Como a latitude do local influencia o ângulo de incidência da radiação solar, em localidades de baixa latitude torna-se vantajoso utilizar coletores solares inclinados, na medida em que há uma redução do ângulo de incidência ${ }^{1}$ da radiação e uma consequente elevação da irradiância na cobertura de vidro.

Há uma contribuição significativa de pesquisas baseadas no desenvolvimento ou adaptação de modelos matemáticos do comportamento de chaminés solares, de forma a prever o fluxo de ar proporcionado pelo sistema. Esses modelos baseiam-se em hipóteses simplificadas dos fenômenos físicos que ocorrem em uma chaminé solar. Tais hipóteses são necessárias, devido à altíssima complexidade existente no fenômeno real, sendo tolerável, portanto, certo grau de desvio nos resultados obtidos. De acordo com Adam (2003), é usual obter diferenças de até $20 \%$ entre dados medidos e calculados. Parte dessas pesquisas faz uso de programas de desempenho térmico e energético, em especial de dinâmica computacional de fluidos (CFD).

Um dos primeiros trabalhos a avaliar a influência da inclinação da chaminé sobre seu desempenho

\footnotetext{
${ }^{1}$ Contado a partir da normal da superfície.
} 
foi o artigo de Bansal et al. (1993). Para tal avaliação, os autores desenvolveram um modelo matemático em regime térmico estacionário, considerando diferentes tamanhos de abertura da chaminé, para as condições climáticas da cidade de Jaipur, Índia (26 $53^{\prime}$ latitude norte). O modelo permite estimar a temperatura da placa absorvedora, a vazão e a temperatura do ar no canal da chaminé. Os melhores resultados indicaram um fluxo de ar de $331 \mathrm{~m}^{3} / \mathrm{h}$ para um coletor solar de $2,25 \mathrm{~m}^{2}, 0,15 \mathrm{~m}$ de profundidade do canal de ar, $30^{\circ}$ de inclinação entre o coletor e a horizontal, e $1.000 \mathrm{~W} / \mathrm{m}^{2}$ de irradiância solar no plano do vidro.

Também na Índia, Mathur, Mathur e Anupma (2006) usaram métodos experimentais e teóricos para investigar os efeitos do ângulo de inclinação do coletor na taxa de ventilação de uma chaminé solar. $\mathrm{O}$ estudo teórico consistiu no desenvolvimento de três equações de balanço de energia - para o absorvedor, o vidro e o ar. O experimento teve por objetivo servir de parâmetro para a calibração da solução teórica. Os resultados mostraram um ângulo ótimo de inclinação do coletor variando entre $45^{\circ}$ e $60^{\circ}$, dependendo da latitude. $\mathrm{O}$ modelo teórico estimou uma velocidade média do ar de $0,18 \mathrm{~m} / \mathrm{s}$, para uma chaminé de seção transversal de $1,0 \mathrm{~m} \mathrm{x} 0,35 \mathrm{~m}$, a $45^{\circ}$ de inclinação, submetida a uma irradiância solar de $750 \mathrm{~W} / \mathrm{m}^{2}$ e à temperatura do ar exterior de $40{ }^{\circ} \mathrm{C}$.

$\mathrm{O}$ presente artigo tem por objetivo apresentar e discutir procedimentos estimativos do potencial de uso de chaminés solares para promover a ventilação natural em edificações de baixa altura, localizadas em regiões de baixa latitude.

\section{Materiais e métodos}

\section{Procedimento experimental}

Desenvolveu-se um estudo experimental através da construção de uma célula de teste na cidade de São Carlos, SP $\left(22^{\circ}\right.$ latitude sul $)$, submetida a condições climáticas reais. A célula foi construída em tijolos cerâmicos, com as seguintes dimensões: 2,7 $\mathrm{m} \times 1,6 \mathrm{~m} \times 2,3 \mathrm{~m}$ (Figura 2). A abertura de entrada de ar encontra-se na fachada sul, a 0,3 m acima do nível do piso, com área efetiva de abertura de $0,14 \mathrm{~m}^{2}$.

A chaminé solar do experimento tem seção retangular e possui um coletor de inclinação variável, voltado para o norte, com comprimento e largura de $1 \mathrm{~m}$, e $0,18 \mathrm{~m}$ de espessura do canal. A placa absorvedora consiste em uma folha de alumínio de $1 \mathrm{~mm}$ de espessura, pintada de preto, com aletas em sua face inferior (Figura 3). As aletas têm a função de aumentar a área de transferência de calor entre a placa e o ar. Elas formam um canal fisicamente independente, aquecido pelo absorvedor por condução. $\mathrm{O}$ coletor é coberto por uma lâmina de vidro incolor comum e protegido nas laterais e base por uma camada de $5 \mathrm{~cm}$ de poliuretano, para isolamento térmico do conjunto.

Para maximizar a incidência de radiação solar sobre o coletor ao longo do ano, há um mecanismo de inclinação regulável, que permite variação entre $0^{\circ}$ e $45^{\circ}$ em relação ao plano horizontal, englobando os melhores ângulos para a latitude do local. Utilizou-se um extensor acoplado à chaminé, de modo a manter a altura total do conjunto em $1,80 \mathrm{~m}$, independentemente da inclinação do coletor. As aberturas de saída do ar encontram-se nas fachadas norte e sul, na parte superior da extensão vertical, e possuem área efetiva de abertura igual à entrada de ar (Figura 2).

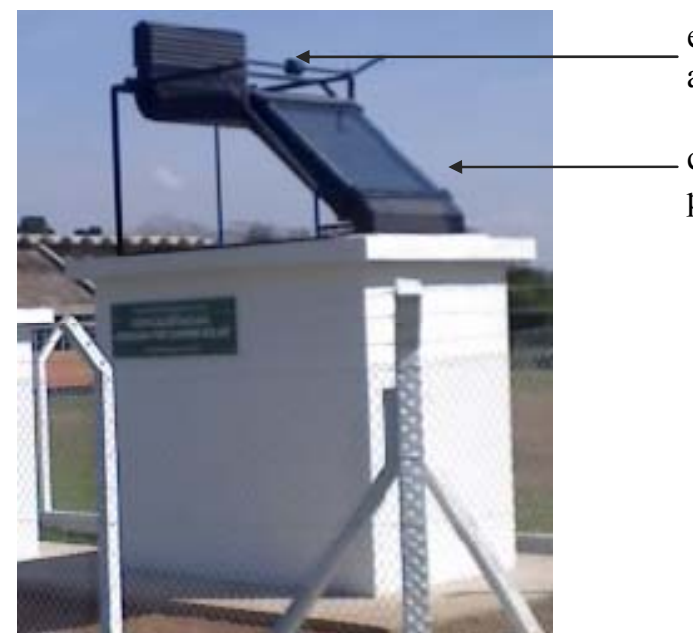

extensor da chaminé e aberturas de saída do ar coletor solar (voltado para o norte)

Figura 2 - Célula de teste experimental de uma chaminé solar inclinada 


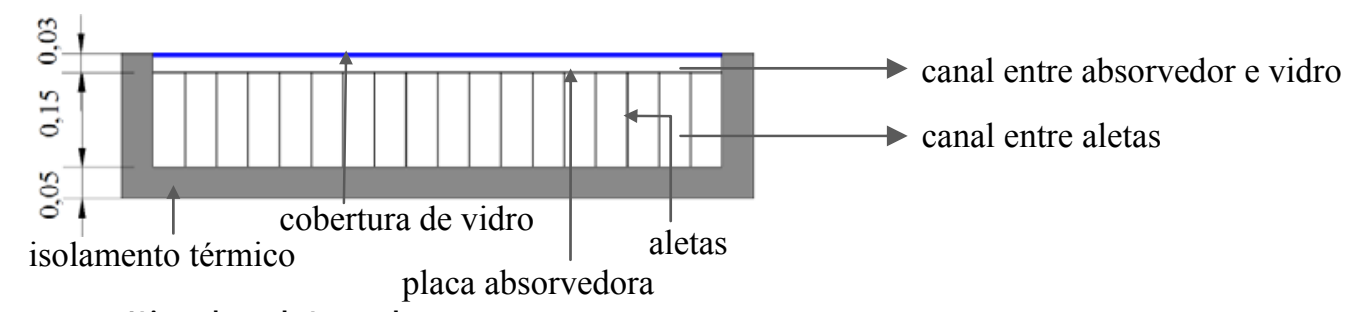

Figura 3 - Corte esquemático do coletor solar

O período de monitoramento compreendeu de março a agosto de 2010. Para cada mês, ajustou-se o ângulo de inclinação do coletor solar, de forma a posicioná-lo na inclinação para máxima irradiância, de acordo com a altura angular do sol média do mês, ao meio-dia.

Os seguintes dados foram monitorados: temperaturas superficiais na placa absorvedora, nas aletas e na superfície interna do vidro (termoresistores com incerteza de $0,2{ }^{\circ} \mathrm{C}$ ); e temperatura e velocidade do ar no canal entre o vidro e o absorvedor e no canal entre aletas (termoanemômetros com incerteza de 3\%). Os pontos de monitoramento foram posicionados próximo à entrada e à saida de ar do coletor solar, tanto no canal entre o vidro e o absorvedor como no canal entre aletas. O tratamento de dados consistiu no cálculo de médias horárias, sendo calculada, para cada variável, uma média entre os pontos a diferentes alturas.

Dados climáticos externos - incluindo temperatura de bulbo seco (TBS), umidade relativa do ar, velocidade e direção do vento e irradiância horizontal - foram obtidos na estação climatológica do Instituto Nacional de Meteorologia (INMet), localizada a $200 \mathrm{~m}$ da célula de teste. As irradiâncias solares direta e difusa sobre o plano inclinado foram calculadas com base em modelos teóricos consagrados na literatura especializada, publicados por Muneer (2004).

\section{Calibração dos modelos teóricos}

Para avaliação do desempenho da chaminé solar, desenvolveram-se predições teóricas por meio de dois métodos:
(a) aplicação de um modelo matemático; e
(b) uso de simulação computacional.

Para aferir as soluções teóricas adotadas, realizouse um processo de calibração, através de comparação com os resultados experimentais. $\mathrm{O}$ processo consistiu em selecionar modelos teóricos de cálculo de diversos coeficientes e adotar os que produziram resultados mais próximos aos valores de fluxo de ar medidos no experimento. Como dados de entrada dos modelos, utilizaram-se as características geométricas e as propriedades físicas dos materiais similares ao experimento desenvolvido em São Carlos (Tabela 1). Nessa etapa, considerou-se apenas o conjunto do coletor solar e da chaminé, de forma a permitir a análise do conjunto como um sistema de escoamento em dutos.

A calibração foi realizada no dia 11 de março de 2010 (Tabela 2). Entre os resultados experimentais coletados, esse mês foi escolhido pelo fato de ser estação de verão, período em que a ventilação natural é uma estratégia importante para promover conforto térmico.

Tabela 1 - Dados de entrada dos modelos teóricos

\begin{tabular}{l|c}
\hline \multicolumn{1}{c|}{ Parâmetro } & Dado de entrada \\
\hline Dimensões do coletor solar & $\begin{array}{c}1 \mathrm{~m} \mathrm{x} 1 \mathrm{~m} \text { de base e } 0,18 \mathrm{~m} \mathrm{de} \\
\text { profundidade do canal }\end{array}$ \\
\hline Altura da chaminé solar & $\begin{array}{c}\text { Altura total do conjunto de } \\
1,80 \mathrm{~m}, \text { incluindo extensor }\end{array}$ \\
\hline $\begin{array}{l}\text { Inclinação do coletor com a horizontal (para } \\
\text { máxima irradiância no plano do vidro) }\end{array}$ & $20^{\circ}$ \\
\hline Condutividade térmica do isolante & $0,03 \mathrm{~W} / \mathrm{m} . \mathrm{K}$ \\
\hline Fator solar do vidro & 0,86 \\
\hline Transmitância térmica do vidro & $5,78 \mathrm{~W} / \mathrm{m}^{2} . \mathrm{K}$ \\
\hline Emissividade da face externa do vidro & 0,84 \\
\hline Absortância da placa absorvedora & 0,80 \\
\hline Emissividade da placa absorvedora & 0,95 \\
\hline
\end{tabular}


Tabela 2 - Resumo dos dados climáticos de São Carlos (INMet)

\begin{tabular}{l|c}
\hline \multicolumn{2}{c}{ Dados climáticos - 11/03/2010 } \\
\hline TBS máxima $\left({ }^{\circ} \mathrm{C}\right)$ & 29,7 \\
TBS mínima $\left({ }^{\circ} \mathrm{C}\right)$ & 17,3 \\
Irradiância horizontal global máxima $\left(\mathrm{W} / \mathrm{m}^{2}\right)$ & 966 \\
Irradiância horizontal direta máxima $\left(\mathrm{W} / \mathrm{m}^{2}\right)$ & 435 \\
Irradiância horizontal difusa máxima $\left(\mathrm{W} / \mathrm{m}^{2}\right)$ & 531 \\
Direção predominante do vento & Noroeste \\
Velocidade média do vento a $10 \mathrm{~m}$ de altura $(\mathrm{m} / \mathrm{s})$ & 1,6 \\
\hline
\end{tabular}

Tabela 3 - Coeficientes de pressão obtidos em ensaios em túnel de vento

\begin{tabular}{c|c|c|c}
\hline \multirow{2}{*}{$\begin{array}{c}\text { Direção do } \\
\text { vento }\end{array}$} & $\begin{array}{c}\text { Abertura de } \\
\text { entrada do ar }\end{array}$ & \multicolumn{2}{|c}{ Aberturas de saída do ar } \\
\cline { 2 - 4 } & Cp (Sul) & Cp (Sul) & Cp (Norte) \\
\hline $0^{\circ}$ & $-0,03$ & $-0,48$ & 0,67 \\
$45^{\circ}$ & $-0,14$ & $-0,37$ & 0,71 \\
$90^{\circ}$ & $-0,38$ & $-0,14$ & $-0,14$ \\
$120^{\circ}$ & 0,22 & 1,07 & $-0,17$ \\
$150^{\circ}$ & 0,39 & 0,66 & $-0,36$ \\
$180^{\circ}$ & 0,24 & 0,39 & $-0,30$ \\
\hline
\end{tabular}

Devido às limitações dos modelos teóricos adotados, as aletas foram desconsideradas na volumetria do coletor solar. Em troca, modelou-se o sistema como uma caixa simples, com o absorvedor em contato direto com o isolamento da base. As aletas funcionam como radiador da placa absorvedora; como não foi possível inseri-las no modelo, o calor que seria perdido da placa para as aletas não pôde ser contabilizado. Diferenças na absorção da radiação solar e na resistência térmica devido à ausência de aletas foram levadas em consideração na análise de resultados.

Para quantificar as resistências por ação do atrito presentes na chaminé solar do experimento, as perdas de carga foram calculadas e inseridas nos modelos teóricos, representadas pelo coeficiente de descarga (Cd). Realizou-se o cálculo através da equação de vazão volumétrica (Eq. 1). Para o cálculo, utilizaram-se como dados de entrada os resultados obtidos no monitoramento experimental. $\mathrm{O}$ coeficiente de descarga resultante foi de 0,12 , o que representa as perdas de carga totais da chaminé solar, incluindo as resistências das seções curvas, das aletas do coletor e das aberturas de entrada e saída do ar. Esse valor consiste em uma média dos valores calculados hora a hora, para o período de março de 2010. Nesse período, o número de Reynolds variou entre 1.400 e 4.000, sendo o fluxo de ar no interior da chaminé variável entre regime laminar e turbulento.
Coeficientes de pressão para as aberturas de entrada e saída do ar (Tabela 3) foram obtidos através de ensaios em túnel de vento, em testes desenvolvidos no Laboratório Nacional de Engenharia Civil (LNEC) de Lisboa, Portugal. Realizaram-se os ensaios em um túnel de circuito aberto, com câmara de testes de $2 \mathrm{~m}$ x $3 \mathrm{~m}$ de seção, $9 \mathrm{~m}$ de comprimento e velocidade variável até $18 \mathrm{~m} / \mathrm{s}$.

As medições foram realizadas em um modelo simplificado da célula de teste (sem aletas no coletor), em escala 1:5, para as seguintes direções do vento: $0^{\circ}$ (abertura de entrada do ar a sotavento), $45^{\circ}, 90^{\circ}, 120^{\circ}, 150^{\circ}$ e $180^{\circ}$ (Figura 4 ). Utilizaram-se os valores resultantes como dados de entrada na simulação computacional. No caso do modelo matemático, devido a suas limitações, só foi possível considerar a ação do vento na transferência de calor por convecção sobre o vidro do coletor solar.

A análise de resultados consistiu na comparação entre valores estimados por meio de modelos teóricos (modelo matemático e simulação) com os obtidos experimentalmente, para as seguintes variáveis:

(a) temperaturas superficiais do vidro (Tv) e da placa absorvedora (Tp);

(b) temperatura do ar no canal (Tc); e

(c) vazão volumétrica (Q). 


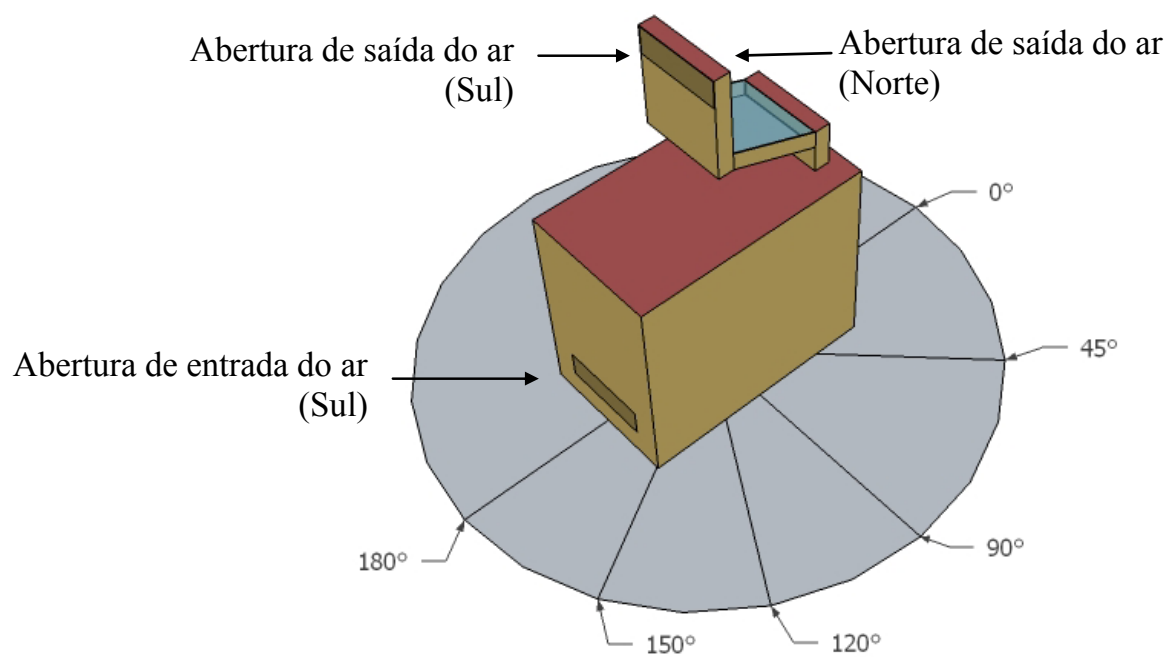

Figura 4 - Posicionamento das aberturas no modelo

\section{Modelo matemático selecionado}

O modelo matemático adotado para análise consiste em três equações de balanço de energia para o vidro, o ar no canal da chaminé e o absorvedor - apresentadas por diversos autores da literatura especializada, entre eles Mathur, Mathur e Anupma (2006), Sakonidou et al. (2008) e Bassiouny e Korah (2009). São três as variáveis desconhecidas no sistema de equações: temperaturas superficiais médias do vidro (Tv) e da placa absorvedora (Tp), e temperatura média do ar no canal da chaminé (Tc). Mathur et al. (2006) apresentam as seguintes equações.

Equação (Eq. 2) do balanço de energia no vidro:

$[$ H. $\alpha v . A v]+[h r p v . A w(T p-T v)]=[h v \cdot A v(T v-$ Tc) $]+[\mathrm{Ut} . \operatorname{Av}(\mathrm{Tv}-\mathrm{Ta})]$

Equação (Eq. 3) do balanço de energia no ar que circula no canal:

$[$ hp. Ap $(\mathrm{Tp}-\mathrm{Tc})]+[\mathrm{hv} \cdot \operatorname{Av}(\mathrm{Tv}-\mathrm{Tc})]=\left[\frac{\mathrm{m} . \mathrm{c} .(\mathrm{Tc}-\mathrm{Tamb})}{\mathrm{Y}}\right]$

Eq. 3

Equação (Eq. 4) do balanço de energia na placa absorvedora:

[H. $\alpha$ p. $\tau$ v. Ap $]=[\mathrm{hp} . \mathrm{Ap}(\mathrm{Tp}-\mathrm{Tc})]+[\mathrm{hrpv} \cdot \mathrm{Ap}(\mathrm{Tp}-$ $\mathrm{Tv})]+[\mathrm{Ub} . \operatorname{Ap}(\mathrm{Tp}-\mathrm{Tamb})]$

Sendo:

$\mathrm{H}=$ irradiância solar no plano do vidro $\left(\mathrm{W} / \mathrm{m}^{2}\right)$;

$\alpha \mathrm{v}=$ absortância solar do vidro (adimensional);

$\mathrm{Av}=$ área do vidro $\left(\mathrm{m}^{2}\right)$;

hrpv $=$ coeficiente de transferência de calor por radiação entre o vidro e a placa absorvedora $\left(\mathrm{W} /\left(\mathrm{m}^{2} . \mathrm{K}\right)\right)$;
$\mathrm{Ap}=$ área da placa absorvedora $\left(\mathrm{m}^{2}\right)$;

$\mathrm{Tp}=$ temperatura média da placa absorvedora $(\mathrm{K})$;

$\mathrm{Tv}=$ temperatura média do vidro $(\mathrm{K})$;

$\mathrm{hv}=$ coeficiente de transferência de calor por convecção entre o vidro e o ar no canal $\left(\mathrm{W} /\left(\mathrm{m}^{2} . \mathrm{K}\right)\right)$;

$\mathrm{Tc}=$ temperatura média do ar no canal $(\mathrm{K})$;

$\mathrm{Ut}=$ coeficiente global de perda de calor do vidro para o ambiente externo $\left(\mathrm{W} /\left(\mathrm{m}^{2} . \mathrm{K}\right)\right)$;

$\mathrm{Ta}=$ temperatura do ar externo $(\mathrm{K})$;

$\mathrm{hp}=$ coeficiente de transferência de calor por convecção entre a placa absorvedora e o ar no canal $\left(\mathrm{W} /\left(\mathrm{m}^{2} . \mathrm{K}\right)\right)$;

$\mathrm{m}=$ vazão mássica $(\mathrm{kg} / \mathrm{s})$;

$\mathrm{c}=$ calor específico do ar na película próxima à placa absorvedora (J/(Kg.K));

$\gamma=$ constante de ponderação da temperatura média do ar no canal $(\gamma=0,74$, conforme sugerido por Ong e Chow, 2003);

Tamb $=$ temperatura média do ar no ambiente ventilado pela chaminé $(\mathrm{K})$;

$\alpha p=$ absortância da placa absorvedora (adimensional);

$\tau \mathrm{V}=$ transmitância ótica do vidro (adimensional); e

$\mathrm{Ub}=$ coeficiente global de transferência de calor da placa absorvedora $\left(\mathrm{W} /\left(\mathrm{m}^{2} \cdot \mathrm{K}\right)\right)$.

Para resolução do modelo matemático, utilizou-se o programa Matlab. Partindo-se de estimativas iniciais das temperaturas desconhecidas (Tv, Tp e Tc) e por meio de sucessivas iterações, obtiveramse os valores finais delas. 
Para possibilitar a resolução do modelo, adotaramse as seguintes hipóteses: considerou-se o ar incompressível, em fluxo laminar e sob regime estacionário; avaliaram-se todas as propriedades físicas do fluido que constitui a película a uma temperatura média entre o fluido e a superfície mais próxima.

No processo de calibração, abordaram-se diferentes modelos de cálculo das seguintes variáveis:

(a) coeficiente de transferência de calor por convecção entre o vidro e o ar (hv) e entre o absorvedor e o ar (hp);

(b) temperatura do céu (Tceu);

(c) vazão volumétrica no canal (Q); e

(d) coeficiente de descarga (Cd).

As equações cujos resultados mais se aproximaram aos dados medidos no experimento foram incorporadas ao modelo matemático.

\section{Simulação computacional}

As simulações computacionais foram realizadas pelo modelo para cálculo de fluxo de ar do programa EnergyPlus, denominado AirflowNetwork. Os cálculos realizados pelo programa baseiam-se na hipótese de que as temperaturas superficiais e do ar são uniformemente distribuídas dentro de uma mesma zona térmica, não havendo possibilidade de desenvolver uma análise ponto a ponto no interior da chaminé. A maioria dos trabalhos teóricos sobre o desempenho de chaminés solares também se baseia nessa hipótese. Além disso, Chungloo e Limmeechokchai (2006) analisaram experimentalmente o assunto e obtiveram boa concordância entre a distribuição da temperatura do ar ao longo do canal e a meia altura.

Para calibração do modelo de simulação, elaborouse primeiramente um modelo tridimensional da célula de teste adotada na etapa experimental, tendo esse modelo as mesmas características geométricas e propriedades físicas dos materiais do experimento (Tabela 1).

O EnergyPlus oferece três opções de algoritmo para cálculo de coeficiente de convecção em superfícies internas e cinco opções para superfícies externas. Testaram-se todos os algoritmos, sendo escolhidas as opções mais apropriadas para simulação da chaminé solar, que consistiram nos algoritmos Detailed para as superfícies internas e TARP (Thermal Analysis Research Program) para as externas. Esses algoritmos correlacionam o coeficiente de transferência de calor com a orientação da superfície e a diferença entre a temperatura do ar na zona térmica e na superfície. Adotam equações de transferência de calor por convecção natural para superfícies horizontais, verticais ou inclinadas, voltadas para cima quando aquecidas ou para baixo quando resfriadas (ENERGYPLUS, 2010).

Para a realização das simulações, criou-se um arquivo climático em formato epw (EnergyPlus weather data file), com base nos dados climáticos adquiridos na estação climatológica do INMet (Tabela 2).

Para que fosse possível verificar os efeitos do vento nas previsões teóricas, realizaram-se simulações com e sem vento. Para contabilizar corretamente os efeitos da ventilação por ação dos ventos, inseriram-se como dados de entrada os coeficientes de pressão das aberturas de entrada e saída do ar obtidos nos ensaios em túnel de vento com barreira (Tabela 3). No caso sem vento, a velocidade do ar foi zerada no arquivo climático.

As perdas de carga por atrito foram contabilizadas através do coeficiente de descarga adotado para as aberturas. Assim como no modelo matemático, também para as simulações os coeficientes de descarga estimados com base nos resultados experimentais foram comparados com o valor de 0,57 sugerido por Andersen (1995).

\section{Resultados teóricos}

\section{Calibração do modelo matemático}

A primeira análise empreendida para calibração do modelo matemático consistiu na comparação entre resultados experimentais e valores estimados por diferentes equações de cálculo para os coeficientes de transferência de calor por convecção entre o vidro e o ar (hv) e entre a placa absorvedora e o ar (hp). Os resultados para temperatura superficial do vidro (Figura 5) indicaram que o hv proposto por Bassiouny e Korah (2009) para fluxo laminar (Eq. 5) apresenta valores mais próximos aos dados experimentais, com uma diferença média de apenas 3\% entre os resultados.

$\mathrm{hv}=\frac{\left(0,6 \cdot(\mathrm{Gr} \cdot \cos \theta \cdot \operatorname{Pr})^{1 / 5}\right) \cdot \mathrm{k}}{\mathrm{C}}$

Eq. 5

Sendo:

$\mathrm{Gr}=$ número de Grashof (adimensional);

$\theta=$ inclinação do coletor, a partir da horizontal $\left({ }^{\circ}\right)$;

$\operatorname{Pr}=$ número de Prandtl (adimensional);

$\mathrm{k}=$ condutividade térmica do fluido $(\mathrm{W} /(\mathrm{m} . \mathrm{K}))$; e

$\mathrm{C}=$ comprimento da chaminé $(\mathrm{m})$. 


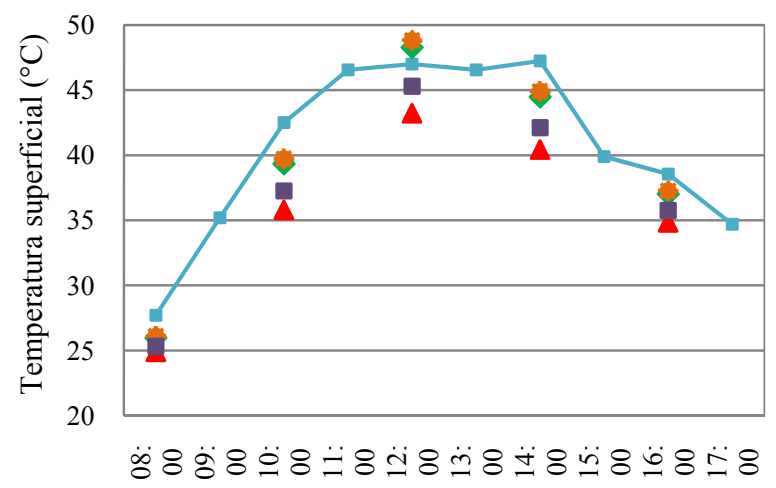

Figura 5 - Temperatura superficial do vidro (ㅇ) - teste de hv e hp

Nota: Legenda:

$\longrightarrow$ Experimento: vidro / absorvedor

$\rightarrow-$ Experimento: aleta

- Mathur, Mathur e Anupma (2006)

- Bassiouny e Korah (2009) - fluxo laminar

- Bassiouny e Korah (2009) - fluxo turbulento

- Incropera e DeWitt (1992)

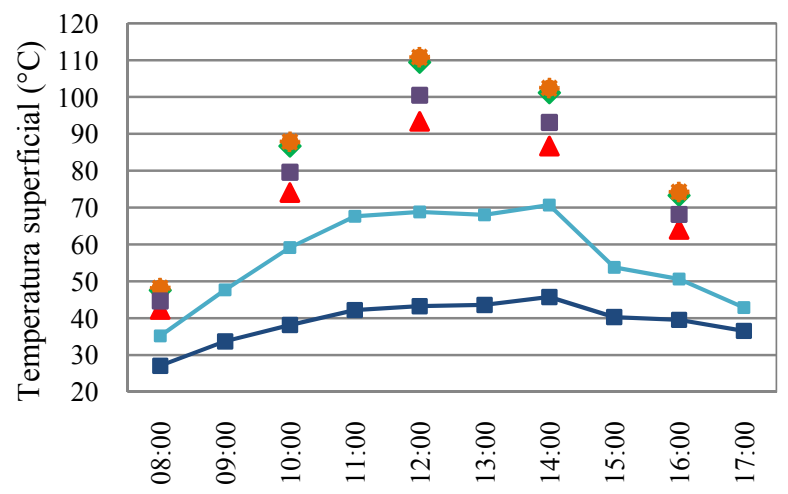

Figura 6 - Temperatura superficial da placa absorvedora (으) - teste de hv e hp

Nota: Legenda:

$\longrightarrow$ Experimento: vidro / absorvedor

$\rightarrow-$ Experimento: aleta

- Mathur, Mathur e Anupma (2006)

- Bassiouny e Korah (2009) - fluxo laminar

- Bassiouny e Korah (2009) - fluxo turbulento

- Incropera e DeWitt (1992)

Os resultados para temperatura superficial da placa absorvedora (Figura 6) indicaram valores estimados $26 \%$ a $48 \%$ acima dos dados medidos, para o período entre $8 \mathrm{~h}$ e $17 \mathrm{~h}$. Tais diferenças podem ser explicadas pelo fato de os cálculos teóricos terem desconsiderado a presença das aletas, o que faz com que o calor absorvido concentre-se na placa, não havendo dissipação para as aletas. $\mathrm{O}$ modelo matemático para cálculo do hp que melhor correspondeu aos resultados experimentais foi o de Mathur, Mathur e Anupma (2006). O modelo de cálculo é semelhante ao apresentado por Bassiouny e Korah (2009) (Eq. 5), entretanto os autores utilizam uma combinação do número de Grashof com a lei de Fourier para condução de calor (Eq. 6).

$\mathrm{Gr}=\frac{\mathrm{g} \cdot \beta \cdot \alpha \mathrm{p} \cdot \tau \mathrm{p} \cdot \mathrm{I} \cdot \mathrm{C}^{4}}{\mathrm{k} \cdot v^{2}}$

Sendo:

$\mathrm{g}=$ aceleração da gravidade $\left(\mathrm{m} / \mathrm{s}^{2}\right)$;

$\beta=$ coeficiente de expansão volumétrica $(1 / \mathrm{K})$;

$\alpha p=$ absortância da placa (adimensional);

$\tau \mathrm{p}=$ transmitância da placa (adimensional); 
$\mathrm{I}=$ irradiância solar no plano do vidro $\left(\mathrm{W} / \mathrm{m}^{2}\right)$; e

$v=$ viscosidade cinemática $\left(\mathrm{m}^{2} / \mathrm{s}\right)$.

A segunda análise empreendida consistiu na comparação entre equações para cálculo de temperatura do céu (Tceu) com os resultados experimentais. Através dos resultados de temperatura superficial do vidro (Figura 7), nota-se que a variação no cálculo de temperatura do céu utilizando céu limpo (nebulosidade igual a zero), realizada através dos modelos propostos por Swinbank (1963), Duffie e Beckman (1991) e EnergyPlus (2010), não ocasionou variações significativas na temperatura superficial do vidro.

Realizou-se uma avaliação da influência da nebulosidade do céu nos resultados de temperatura superficial do vidro, através de testes com o modelo de cálculo de temperatura do céu do EnergyPlus (2010) para céu limpo $(\mathrm{N}=0)$ e para céu com nebulosidade média $(\mathrm{N}=6)$. Para $\mathrm{o}$ segundo caso, as temperaturas superficiais do vidro apresentaram uma aproximação significativa com os dados experimentais (Figura 7), indicando a importância da temperatura do céu e do grau de nebulosidade no cálculo do coeficiente global de perda de calor do vidro para o ambiente externo. A diferença entre dados medidos e calculados, para esse caso, foi de apenas $1 \%$. A equação para o cálculo baseia-se no algoritmo apresentado por Walton (1983 ${ }^{2}$ apud ENERGYPLUS, 2010) (Eq. 7 a 9).

عceu $=\left(0,787+0,764 \cdot \ln \left(\frac{\text { Torv }}{273}\right)(1+\right.$

$\left.0,0224 . N+0,0035 . N^{2}+0,00028 \cdot N^{3}\right)$

Eq. 7

$\mathrm{H}_{\mathrm{IV}}=\varepsilon$ ceu $\sigma \cdot \mathrm{Te}^{4}$

Eq. 8
Tceu $=\left(\frac{\mathrm{H}_{\mathrm{IV}}}{\sigma}\right)^{0,25}$

Eq. 9

Onde:

Eceu = emissividade do céu;

Torv $=$ temperatura de ponto de orvalho $(\mathrm{K})$;

$\mathrm{N}=$ nebulosidade (adimensional - de 0 a 10);

$\mathrm{HIV}=$ radiação infravermelha horizontal $\left(\mathrm{W} / \mathrm{m}^{2}\right)$;

$\Sigma=$ constante de Steffan-Boltzmann $(5,67 \times 10-8$ $\left.\mathrm{W} /\left(\mathrm{m}^{2} \cdot \mathrm{K}^{4}\right)\right)$;

$\mathrm{Te}=$ temperatura do ar externo $(\mathrm{K})$; e

Tceu $=$ temperatura do céu $(K)$.

A terceira análise compreendeu a comparação entre equações de cálculo de vazão volumétrica da chaminé solar $(\mathrm{Q})$ com os resultados experimentais (Figura 8). O coeficiente de descarga utilizado nos cálculos foi de 0,12 , conforme cálculo previamente realizado com base nos resultados experimentais.

O modelo 1 apresentado por Sakonidou et al. (2008) superestimou o fluxo de ar no período diurno em $70 \%$, em média, e o modelo 2 subestimou o fluxo de ar em torno de 69\%. O modelo de cálculo proposto por Mathur, Mathur e Anupma (2006) (Eq. 10) foi o que apresentou vazão volumétrica mais próxima aos dados experimentais, sendo a diferença entre calculo teórico e experimento, para a média diária do período diurno, de 31\%. Ainda assim, os modelos calibrados produziram resultados insatisfatórios, especialmente se for considerado que são usuais diferenças de até $20 \%$ entre dados medidos e calculados (ADAM, 2003).

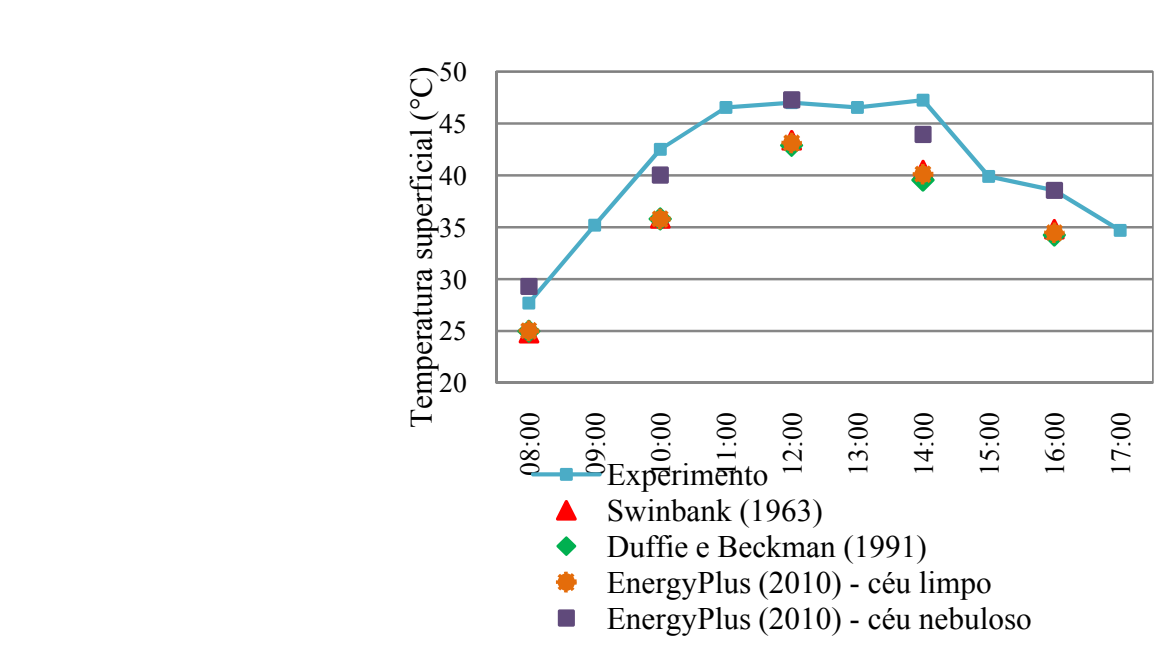

Figura 7 - Temperatura superficial do vidro - teste de Tceu

\footnotetext{
${ }^{2}$ WALTON, G. Thermal Analysis Research Program Reference Manual. National Bureau of Standards, 1983. p. 21. (NBSSIR 83-2655).
} 


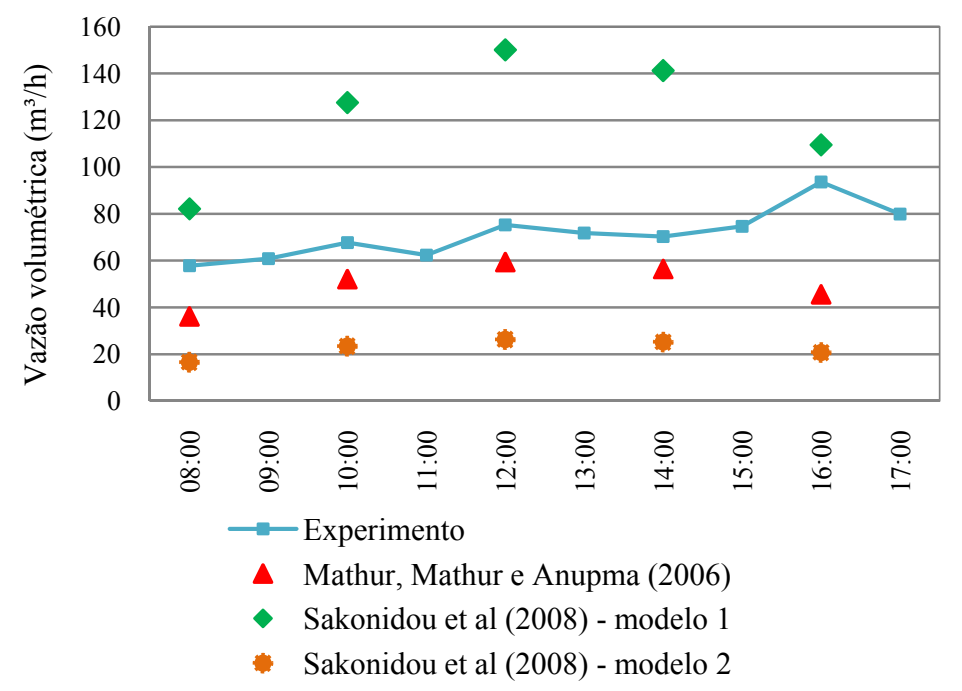

Figura 8 - Vazão volumétrica da chaminé $\left(\mathrm{m}^{3} / \mathrm{h}\right)$

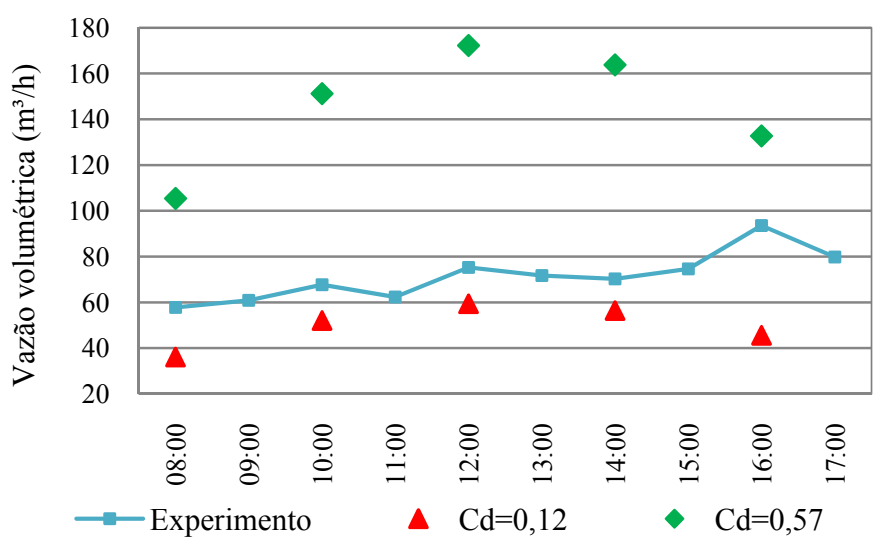

Figura 9 - Vazão volumétrica da chaminé - teste de Cd

$\mathrm{Q}=$ Cd. As. $\sqrt{\frac{2 . \mathrm{g} \cdot \mathrm{C} \cdot \mathrm{sen} \theta \cdot(\mathrm{Tc}-\mathrm{Tamb})}{\left(1+\mathrm{Ar}^{2}\right) \cdot \mathrm{Tamb}}}$

Eq. 10

Sendo:

As = área da seção de saída do ar na chaminé $\left(\mathrm{m}^{2}\right)$; e

$\mathrm{Ar}=$ razão entre a área de saída e a área de entrada da chaminé (adimensional).

A última análise consistiu na comparação entre o coeficiente de descarga calculado com base nos resultados experimentais $(\mathrm{Cd}=0,12)$ e o coeficiente de descarga específico para movimento de ar por impulsão térmica calculado por Andersen (1995) $(\mathrm{Cd}=0,57)$ (Figura 9). Para o primeiro caso, a diferença entre valores estimados e medidos, considerando a média diária do período diurno, foi de $31 \%$, conforme mencionado acima. No caso do coeficiente de descarga calculado por Andersen (1995), a diferença média subiu para 102\%.

O coeficiente de transferência de calor por convecção é considerado o coeficiente de transferência de calor mais importante na análise de uma chaminé solar (ADAM, 2003), pois a maior parte da troca de calor, neste sistema, dá-se pelo ar do canal. Comparativamente, a perda de calor por radiação pelo vidro e por condução pela parte de trás do canal não são consideráveis. Entretanto, a escolha do coeficiente de descarga na análise de calibração mostrou maior impacto nas predições do que a escolha do coeficiente de transferência de calor por convecção. Esse resultado mostra que maior atenção deve ser tomada na escolha do coeficiente de descarga, o que contraria a prática corrente de assumir um valor próximo de 0,6 , independentemente do detalhamento das aberturas e do canal da chaminé.

\section{Calibração do modelo computacional}

As simulações computacionais foram realizadas com os algoritmos de cálculo de coeficientes de convecção considerados mais adequados às transferências de calor em uma chaminé solar, 
disponíveis no programa EnergyPlus (algoritmos Detailed para as superfícies internas e TARP para as externas). O coeficiente de descarga utilizado nas simulações consistiu no valor de 0,12 , obtido através dos resultados experimentais. Os resultados obtidos nas simulações foram comparados com os melhores resultados obtidos na análise do modelo matemático (em Calibração do modelo matemático) e com os resultados da etapa experimental.

As predições de temperatura superficial do vidro apresentaram boa concordância com o experimento, pois a diferença média entre os resultados simulados e medidos foi de apenas 3\% para o período entre $8 \mathrm{~h}$ e $17 \mathrm{~h}$ (Figura 10). Os resultados ficaram próximos aos obtidos pela aplicação do modelo matemático. Já os valores estimados por simulação para a temperatura superficial da placa absorvedora não apresentaram concordância tão satisfatória, ficando $15 \%$ acima dos dados medidos para o mesmo período (Figura 11). Se comparados aos resultados do modelo matemático, no entanto, a simulação computacional apresentou melhor desempenho, já que as diferenças entre modelo matemático e experimento ficaram em torno de $30 \%$.

Para a temperatura do ar no canal da chaminé, os valores previstos por simulação ficaram próximos à média entre os valores monitorados nos dois canais do experimento (canal entre vidro e absorvedor e canal entre aletas), sendo a diferença média entre resultados de apenas 1\% (Figura 12). Já os valores previstos pelo modelo matemático ficaram bastante próximos à temperatura do ar no canal entre aletas. A diferença entre valores previstos pelo modelo matemático e a média entre os valores monitorados nos dois canais foi de $11 \%$.

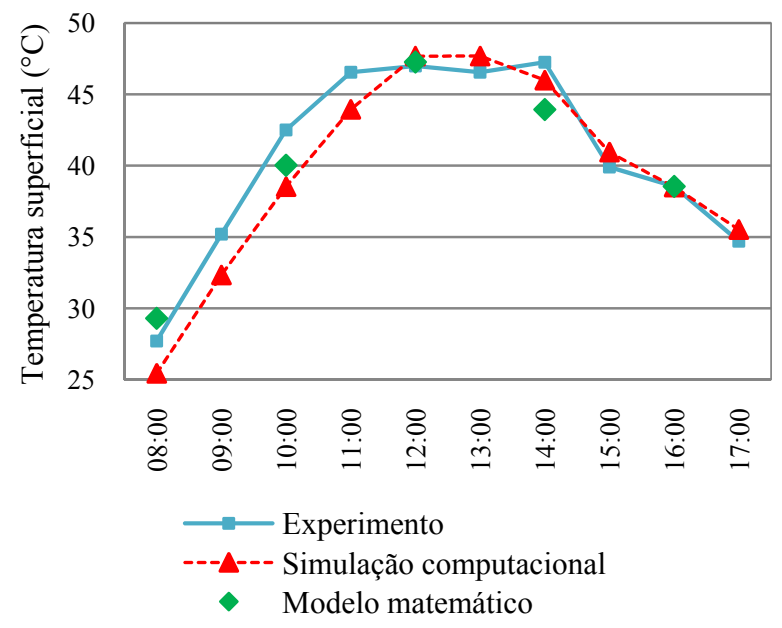

Figura 10 - Temperatura superficial do vidro (으)

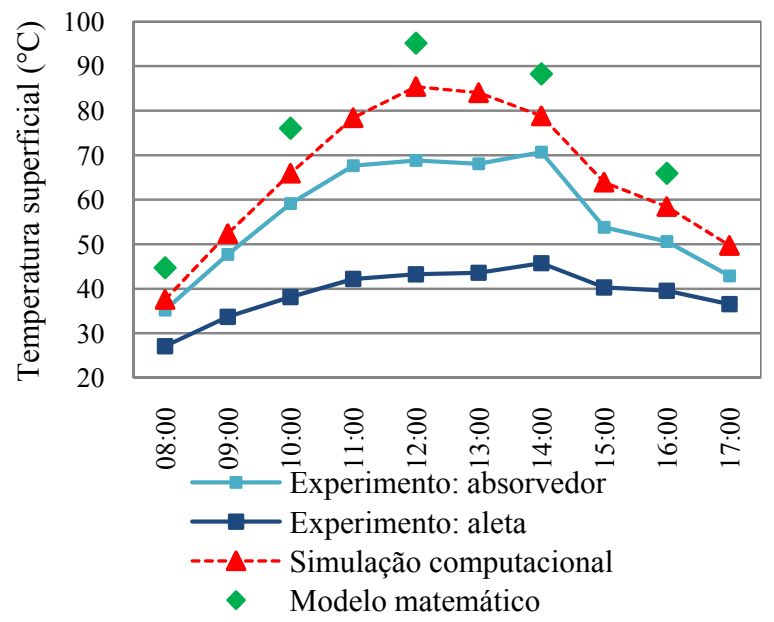

Figura 11 - Temperatura superficial do absorvedor (ㅇ) 


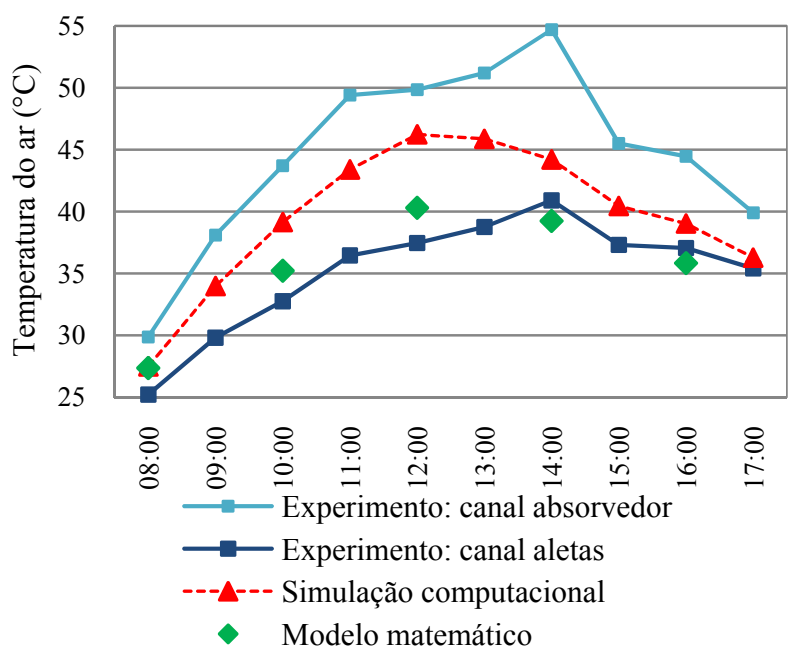

Figura 12 - Temperatura do ar no canal da chaminé (C)

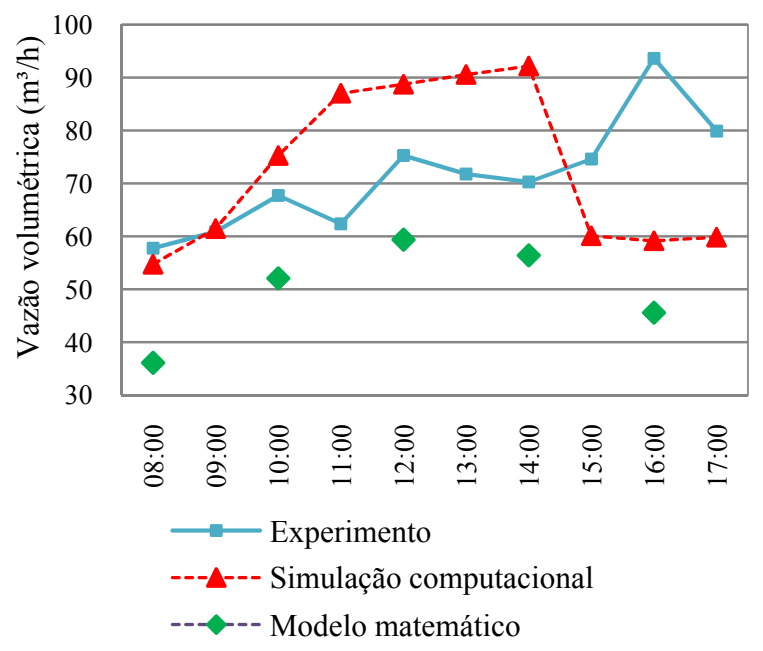

Figura 13 - Vazão volumétrica da chaminé $\left(\mathrm{m}^{3} / \mathrm{h}\right)$

Os resultados de vazão volumétrica no canal da chaminé mostraram, tanto para a curva obtida pela simulação computacional como para a obtida pelos resultados experimentais, uma grande variação no fluxo de ar ao longo do tempo (Figura 13). Essa variação foi provocada pela mudança constante na velocidade e direção do vento na célula de teste. Como os cálculos pelo modelo matemático não consideraram a interferência do vento, a vazão volumétrica resultante dependeu apenas da temperatura do ar externo e da irradiância solar.

Ao comparar simulação computacional e experimento, pode-se notar diferenças nas taxas de variação dos resultados. A simulação subestima os resultados durante os períodos da manhã e do fim da tarde, e superestima ao meio-dia, horário de pico de radiação solar (Tabela 4). A diferença entre médias diárias do período diurno ficou em
$7 \%$. No caso do modelo matemático, os valores obtidos foram sempre inferiores aos experimentais, o que pode ter ocorrido, em parte, devido à influência do vento, que não pôde ser considerada por conta de limitações do modelo. Para este caso, a diferença entre médias diárias ficou em 31\%.

Por fim, foram realizadas simulações com e sem vento e com coeficientes de descarga de 0,12 (resultados experimentais) e de 0,57 (sugerido por Andersen, 1995) (Figura 14). A adoção de um coeficiente de descarga de 0,12 , um valor à primeira vista surpreendentemente baixo, respondeu bem à calibração. A comparação entre simulações com vento, para coeficientes de descarga de 0,12 e de 0,57 , mostrou diferenças de até $18 \%$ entre os dois resultados, sendo o coeficiente de 0,12 o que apresenta resultados mais próximos aos dados medidos. 
Tabela 4 - Vazão volumétrica no canal da chaminé

\begin{tabular}{|c|c|c|c|c|c|}
\hline $\begin{array}{c}\text { Hora } \\
(11 / 03 / 2010)\end{array}$ & $\begin{array}{l}\text { Experimento } \\
\left(\mathrm{m}^{3} / \mathrm{h}\right)\end{array}$ & $\begin{array}{c}\text { Simulação } \\
\text { computacional } \\
\left(\mathrm{m}^{3} / \mathbf{h}\right)\end{array}$ & $\begin{array}{c}\text { Diferença } \\
\text { (\%) }\end{array}$ & $\begin{array}{c}\text { Modelo } \\
\text { matemático } \\
\left(\mathrm{m}^{3} / \mathrm{h}\right)\end{array}$ & $\begin{array}{c}\text { Diferença } \\
(\%)\end{array}$ \\
\hline $8 \mathrm{~h} 00$ & 57,77 & 54,71 & $-6 \%$ & 36,10 & $-60 \%$ \\
\hline $9 \mathrm{~h} 00$ & 60,88 & 61,45 & $1 \%$ & - & - \\
\hline $10 \mathrm{~h} 00$ & 67,70 & 75,25 & $10 \%$ & 52,04 & $-30 \%$ \\
\hline $11 \mathrm{~h} 00$ & 62,36 & 87,01 & $28 \%$ & - & - \\
\hline $12 \mathrm{~h} 00$ & 75,25 & 88,71 & $15 \%$ & 59,35 & $-27 \%$ \\
\hline $13 \mathrm{~h} 00$ & 71,77 & 90,55 & $21 \%$ & - & - \\
\hline $14 \mathrm{~h} 00$ & 70,26 & 92,16 & $24 \%$ & 56,39 & $-25 \%$ \\
\hline $15 \mathrm{~h} 00$ & 74,61 & 60,09 & $-24 \%$ & - & - \\
\hline $16 \mathrm{~h} 00$ & 93,60 & 59,15 & $-58 \%$ & 45,57 & $-105 \%$ \\
\hline $17 \mathrm{~h} 00$ & 79,85 & 59,84 & $-33 \%$ & - & - \\
\hline
\end{tabular}

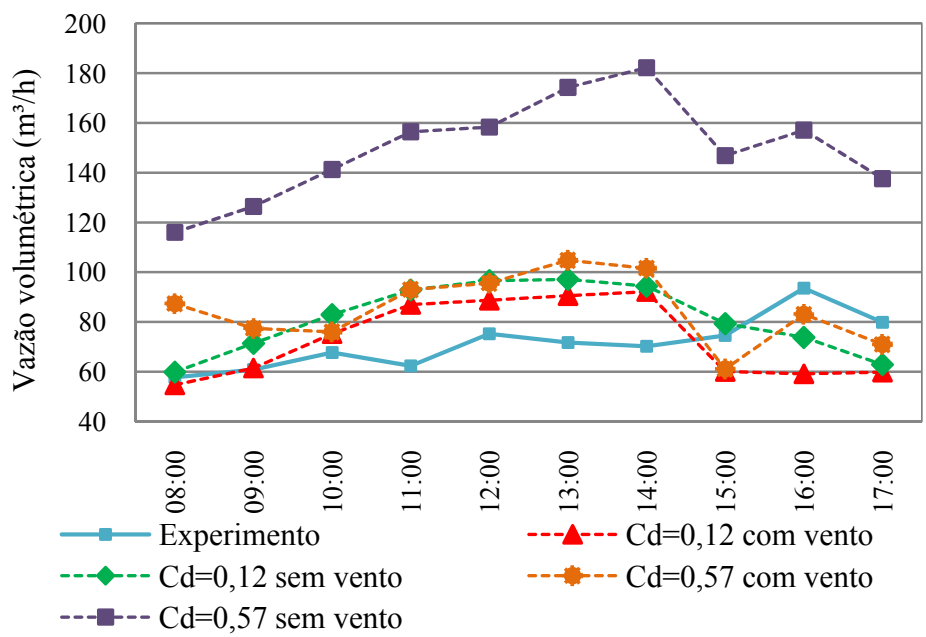

Figura 14 - Vazão volumétrica da chaminé - teste de Cd e da presença ou ausência de ventos

Esses resultados, juntamente com os obtidos pela análise realizada através do modelo matemático (Figura 9) mostram o grande impacto causado pela escolha adequada do coeficiente de descarga sobre o resultado final das previsões teóricas.

A comparação entre resultados de simulações com e sem vento permite traçar uma análise simplificada dos efeitos do vento sobre o desempenho da chaminé solar. Para o caso das simulações com coeficiente de descarga de 0,12 , a ausência de ventos provocou um acréscimo médio de $13 \%$ na vazão volumétrica da chaminé. Já no caso das simulações com coeficiente de descarga de 0,57 , a ausência de ventos provocou um acréscimo médio de $91 \%$ na vazão volumétrica. Os resultados mostram que $o$ vento interferiu negativamente no desempenho da chaminé solar. De fato, a direção do vento para o período analisado estava predominantemente contrária à abertura de entrada de ar da célula de teste, variando entre $290^{\circ}$ e $330^{\circ}$. Sabe-se que o valor do coeficiente de descarga é inversamente proporcional à perda de carga do sistema. Em vista disso, no caso do coeficiente de descarga igual a 0,12 , o incremento provocado pela ausência de ventos foi menor devido à elevada perda de carga da chaminé.

\section{Conclusões}

A presente pesquisa teve como intuito apresentar modelos teóricos para a estimativa do potencial de ventilação proporcionado por chaminés solares. Para a calibração dos modelos selecionados, utilizaram-se como referência monitoramentos experimentais em uma célula de teste.

É importante mencionar as incertezas originadas do sistema de monitoramento usado no procedimento experimental, especialmente dos anemômetros de fio quente, que podem ter contribuído para as diferenças observadas entre experimento e modelos teóricos. Também contribui para esse fato a imprecisão dos dados de entrada utilizados nos modelos teóricos, como transmitância térmica do vidro e condutividade térmica do isolante, por exemplo. Apesar disso, os 
modelos calibrados produziram resultados satisfatórios, especialmente se for considerado que são usuais diferenças de até $20 \%$ entre dados medidos e calculados (ADAM, 2003).

Os dois modelos teóricos adotados (cálculo e simulação) mostraram ser ferramentas apropriadas para avaliação de desempenho de uma chaminé solar, desde que as perdas de carga da chaminé sejam corretamente previstas. Mudanças no valor do coeficiente de descarga afetam linearmente os resultados de fluxo de ar obtidos, sendo alta, portanto, a sensibilidade dos modelos para esse parâmetro.

Comparando os dois modelos, pode-se concluir que a simulação computacional apresentou melhor concordância com os dados experimentais, sendo, portanto, mais viável e confiável para uso na avaliação de outros parâmetros de projeto e para o desenvolvimento de estudos comparativos de chaminés solares.

A ação dos ventos sobre o funcionamento da chaminé solar também é uma questão a ser cuidadosamente avaliada. Se corretamente aproveitados, eles podem contribuir positivamente para a ventilação natural do ambiente interno em edificações. Ensaios aqui apresentados demonstraram diferenças de até $91 \%$ na vazão volumétrica da chaminé, resultantes da comparação de casos com e sem vento. $\mathrm{O}$ uso da chaminé solar como estratégia de ventilação natural, no entanto, justifica-se quando a ocorrência de ventos é muito baixa ou nula, pois, nessas situações, se torna inviável o uso de estratégias de ventilação por ação dos ventos.

\section{Referências}

ADAM, Z. On the Performance of Solar

Chimneys: with particular reference on the prediction of flow rate. PhD (Doctoral dissertation) - Department of Architecture, Faculty of Engineering, Osaka University, Osaka, 2003.

ANDERSEN, K. T. Theoretical Considerations on Natural Ventilation by Thermal Buoyancy.

ASHRAE Transactions, v. 101, n. 2, p. 1103$1117,1995$.

BANSAL, N.; MATHUR, R.; BHANDARI, M. Solar Chimney for Enhanced Stack Ventilation. Building and Environment, v. 28, n. 3, p. 373377, jul. 1993.

BASSIOUNY, R.; KORAH, N. An Analytical and Numerical Study of Solar Chimney Use for Room Natural Ventilation. Energy and Buildings, v. 40, n. 5, p. 865-873, maio 2008 .
BASSIOUNY, R.; KORAH, N. Effect of Solar Chimney Inclination Angle on Space Flow Pattern and Ventilation Rate. Energy and Buildings, v. 39, n. 2, p. 190-196, fev. 2009.

CHEN, Z. D. et al. An Experimental Investigation of a Solar Chimney Model With Uniform Wall Heat Flux. Building and Environment, v. 38, n. 7, p. 893-906, jul. 2003.

CHUNGLOO, S.; LIMMEECHOKCHAI, B. A Numerical Study of Natural Ventilation in Buildings: utilized solar chimney and cool ceiling. In: JOINT INTERNATIONAL CONFERENCE ON "SUSTAINABLE ENERGY AND ENVIRONMENT”, 2., Bangkok, 2006. Proceedings... Bangkok: SEE, 2006.

CÓSTOLA, D. Ventilação por Ação do Vento no Edifício: procedimentos para quantificação. São Paulo, 2006. Dissertação (Mestrado em Arquitetura) - Faculdade de Arquitetura e Urbanismo, Universidade de São Paulo, São Paulo, 2006.

DUFFIE, J.; BECKMAN, W. Solar Engineering or Thermal Processes. 2. ed. New York: John Wiley \& Sons, Inc., 1991.

\section{ENERGYPLUS. EnergyPlus Engineering}

Reference: the reference to EnergyPlus calculations. US Department of Energy, 2010.

GIVONI, B. Passive and Low Energy Cooling of Buildings. London: John Wiley \& Sons, 1994.

INCROPERA, F.; DEWITT, D. Fundamentos de transferência de calor e de massa. (Trad.

Horácio Macedo) 3. ed. Rio de Janeiro: LTC Livros Técnicos e Científicos Editora S.A., 1992.

MARQUES DA SILVA, F. V. Ventilação

Natural de Edifícios: turbulência atmosférica. Lisboa, 2003. Tese (Doutorado em Engenharia Mecânica) - Instituto Superior Técnico, Universidade Técnica de Lisboa, Lisboa, 2003.

MATHUR, J.; MATHUR, S.; ANUPMA. Summer Performance of Inclined Roof Solar Chimney for Natural Ventilation. Energy and Buildings, v. 38, n. 10, p. 1156-1163, out. 2006.

MATHUR, J. et al. Experimental investigations on solar chimney for room ventilation. Solar Energy, v. 80, n. 8, p. 927-935, Aug. 2006.

MUNEER, T. Solar Radiation and Daylight

Models. 2. ed. Jordan Hill, Oxford: Elsevier, 2004.

ONG, K. S.; CHOW, C. C. Performance of a Solar Chimney. Solar energy, v. 74, n. 1, p. 1-17, jan. 2003. 
SAKONIDOU, E. P. et al. Modeling of the Optimum Tilt of a Solar Chimney for Maximum Air Flow. Solar Energy, v. 82, n. 1, p. 80-94, jan. 2008.

SWINBANK, W. Long-Wave Radiation from Clear Skies. Quarterly Journal of the Royal Meteorological Society, v. 89, n. 381, p. 339-348, 1963.

\section{Agradecimentos}

Os autores agradecem à Fundação de Amparo à Pesquisa do Estado de São Paulo (Fapesp), pelo apoio financeiro ao desenvolvimento desta pesquisa, e ao Laboratório Nacional de Engenharia Civil (LNEC) de Lisboa, Portugal, em especial ao Eng. Fernando Marques da Silva, pelo apoio no desenvolvimento dos ensaios em túnel de vento.

Revista Ambiente Construído

Associação Nacional de Tecnologia do Ambiente Construído

Av. Osvaldo Aranha, $99-3^{\circ}$ andar, Centro

Porto Alegre - RS - Brasil

CEP $90035-190$

Telefone: +55 (51) 3308-4084

Fax: +55 (51) 3308-4054

www.seer.ufrgs.br/ambienteconstruido

E-mail: ambienteconstruido@ufrgs.br

192 Neves, L. de O.; Roriz, M. 